\title{
Active Damping of LLCL Filters Using PR Control for Grid-Connected Three-Level T-Type Converters
}

\author{
Payam Alemi ${ }^{*}$, Seon-Yeong Jeong ${ }^{*}$, and Dong-Choon Lee ${ }^{\dagger}$ \\ ${ }^{*}$ Department of Electrical Engineering, Yeungnam University, Gyeongsan, Korea
}

\begin{abstract}
In this paper, an active damping control scheme for LLCL filters based on the PR (proportional-resonant) regulator is proposed for grid-connected three-level T-type PWM converter systems. The PR controller gives an infinite gain at the resonance frequency. As a result, the oscillation can be suppressed at that frequency. In order to improve the stability of the system in the case of grid impedance variations, online grid impedance estimation is applied. Simulation and experimental results have verified the effectiveness of the proposed scheme for three-phase T-type AC/DC PWM converters.
\end{abstract}

Key words: Active damping, Grid-connected converter, LLCL filters, PR control

\section{INTRODUCTION}

In recent years, voltage source converters (VSC) have been widely employed for grid-connected applications with the advantage of bidirectional power flow and its ability to control the voltage and power factor. In particular, multilevel converters such as T-type three-level inverters have been used due to their higher performance and efficiency when compared with the two-level converters [1]-[3]. To suppress switching harmonics, a large size filter inductor is needed in the VSC. However, this deteriorates the system dynamic performance and increases the cost of the inductor in high power applications.

Due to the advantages in terms of cost and dynamics, LCL filters are preferred over L filters for grid-connected PWM converters since smaller inductors can be used in the LCL filters. However, there are drawbacks of LCL filters such as the resonance phenomena and the complex control algorithm [4]-[7]. To suppress the filter resonance, a number of passive and active damping methods have been proposed [8]-[16]. The passive damping methods are simple and reliable, but power loss is an issue especially for high power applications [8]-[10]. On the other hand, the active damping schemes do not increase power losses, but the control algorithm is modified to suppress resonance [11]-[17]. In [12], [13], an

Manuscript received Oct. 10, 2014; accepted Dec. 16, 2014

Recommended for publication by Associate Editor Kyo-Beum Lee.

${ }^{\dagger}$ Corresponding Author: dclee@yu.ac.kr

Tel: +82-53-810-2582,Fax: +82-53-810-4767, Yeungnam University

*Department of Electrical Engineering, Yeungnam University, Korea

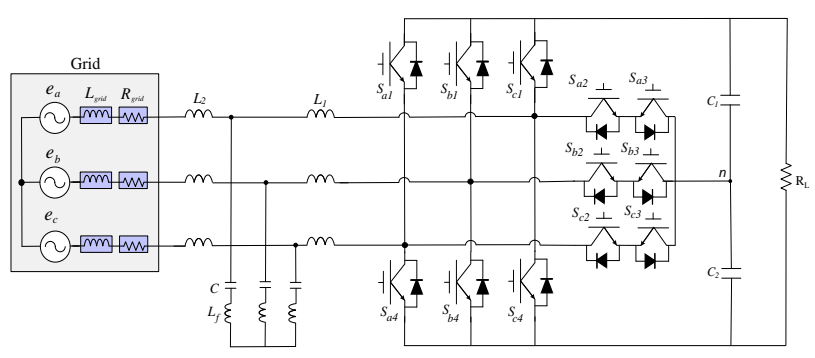

Fig. 1. Grid-connected three-level T-type converters with LLCL filters.

active damping method based on a virtual resistor has been proposed. However, an extra capacitor current sensor is required. In [14], a genetic algorithm has been applied to tune the notch filter for the active damping of LCL filters. Although no extra sensor is needed, the optimization algorithm is complicated. The PR regulator has been discussed for LCL filters in [15], [16]. However, the grid impedance variation has not been investigated which is an issue in the case of a variable grid impedance.

To reduce the inductor size in LCL filters, a new structure for the LLCL filters of single-phase VSCs has been proposed [18]. To suppress the resonance of the LLCL filters, the passive damping method has been employed, where an additional resistor was used [9]-[11].

This paper is an extended version of [16], where an active damping method based on the PR control has been proposed for the LLCL filters of three-level T-type converters. To suppress the resonance in the case of variable grid impedances, the online grid impedance estimation method is 


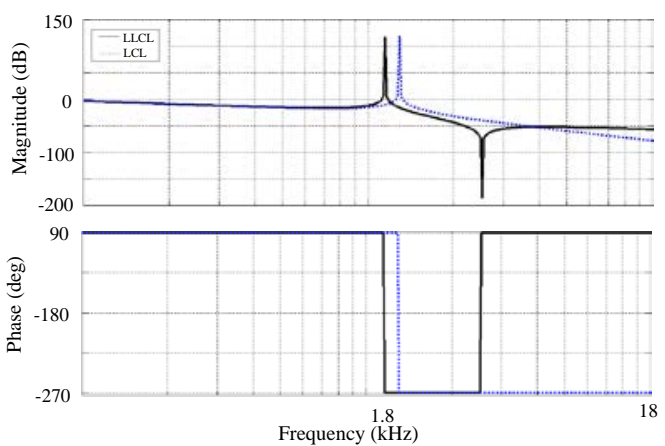

(a)

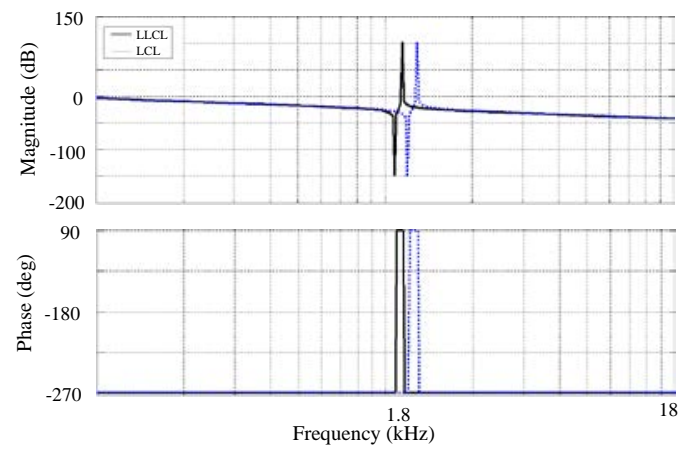

(b)

Fig. 2. Bode plots of transfer functions in LCL and LLCL filters. (a) $G_{1}(s)=I_{g}(s) / V_{i}(s) \cdot$ (b) $G_{2}(s)=I_{c}(s) / V_{i}(s)$.

applied. In addition, the system stability is analyzed to show the validity of the proposed control algorithm. The effectiveness of the proposed method is verified by simulation and experimental results obtained for a three-level T-type converter.

\section{SYSTEM DESCRIPTION}

\section{A. Three-Level T-type AC/DC PWM Converters}

A three-level T-type AC/DC PWM converter is shown in Fig. 1. It is connected to the grid through LLCL filters. The grid is modeled as a sinusoidal voltage source with variable line impedances. A resistive load is connected to the DC output terminal of the converter. For the PWM converter, the voltage equations are expressed in the synchronous reference frame as [19]:

$$
\begin{aligned}
& e_{d e}=R i_{d e}+L \frac{d i_{d e}}{d t}-\omega L i_{q e}+v_{d e} \\
& e_{q e}=R i_{q e}+L \frac{d i_{q e}}{d t}+\omega L i_{d e}+v_{q e}
\end{aligned}
$$

where:

$$
\begin{aligned}
& e_{d e}, e_{q e}: d q \text {-axis grid voltages } \\
& i_{d e}, i_{q e}: d q \text {-axis converter currents } \\
& v_{d e}, v_{q e}: d q \text {-axis converter voltages }
\end{aligned}
$$

$\omega$ : angular frequency of the grid voltage

$R$ : sum of the resistances in the filter inductors $\left(R_{1}+R_{2}\right)$

$L$ : sum of grid- and converter-side inductors $\left(L_{1}+L_{2}\right)$

By aligning the q-axis of the synchronous reference frame to the grid voltage, $e_{d e}=0$. The DC-link voltage dynamics can be expressed as:

$$
C \frac{d v_{d c}}{d t}=i_{D C}-i_{L}
$$

where:

$$
\begin{aligned}
& v_{d c}: \text { DC-link voltage } \\
& i_{D C}: \text { converter-side DC current } \\
& i_{L}: \text { load current }
\end{aligned}
$$

where the losses in the filter and the converter are neglected.

\section{B. LLCL Filters}

In LLCL filters, the transfer functions of the grid and converter currents to the converter voltage are expressed as:

$$
\begin{aligned}
& G_{1}(s)=\frac{I_{g}(s)}{V_{i}(s)}=\frac{L_{f} C s^{2}+1}{\left(L_{f} C\left(L_{1}+L_{2}^{\prime}\right)+L_{1} L_{2}^{\prime} C\right) s^{3}+\left(L_{1}+L_{2}^{\prime}\right) s} \\
& G_{2}(s)=\frac{I_{c}(s)}{V_{i}(s)}=\frac{\left(L_{2}^{\prime}+L_{f}\right) C s^{2}+1}{\left(L_{f} C\left(L_{1}+L_{2}^{\prime}\right)+L_{1} L_{2}^{\prime} C\right) s^{3}+\left(L_{1}+L_{2}^{\prime}\right) s}
\end{aligned}
$$

where:

$$
L_{2}^{\prime}=L_{2}+L_{g}
$$

From (4) and (5), the resonance frequency in the LLCL filters is given by:

$$
f_{\text {res }}=\frac{1}{2 \pi} \sqrt{\frac{L_{1}+L_{2}^{\prime}}{\left(L_{1} \cdot L_{2}^{\prime} \cdot C\right)+\left(L_{1}+L_{2}^{\prime}\right) L_{f} C}}
$$

The frequency responses of the grid and converter currents to the converter voltage are shown in Fig. 2(a) and (b), respectively. It can be seen that the impedance of the LLCL filters is very low near the switching frequency due to the series inductor in the capacitor branch.

\section{Parameter Design of LLCL Filters}

In the design of the filter, some limitations on the parameter values should be considered as follows [6], [8]:

1) The converter-side inductor $L_{1}$ is determined based on the allowable current ripple of the converter.

$$
\frac{V_{d c}}{16 i_{r p_{\text {Max }}} \cdot f_{s w}} \leq L_{1}
$$

Where:

$i_{r p_{M a x}}$ : maximum ripple component in the rated current

$f_{\text {sw }}$ : switching frequency 


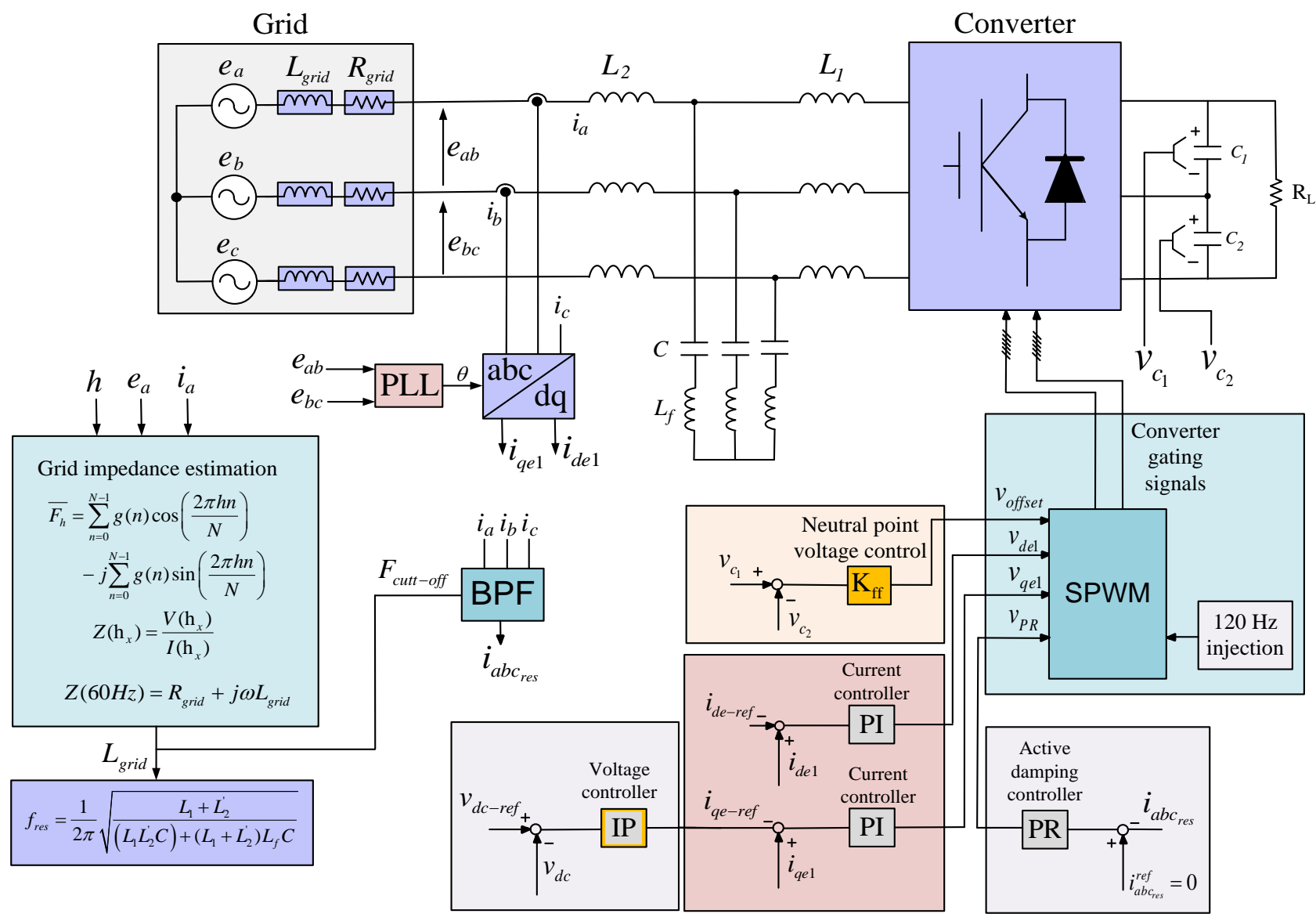

Fig. 3. Control block diagram of the grid-connected PWM converter with LLCL filters.

The grid-side inductor $L_{2}$ is designed according to the IEEE 519-1992 standard recommendations, where harmonic currents higher than the $35^{\text {th }}$ order component should be less than $0.3 \%$ of the fundamental.

2) The capacitor value $C$ is determined based on the reactive power absorbed under the rated condition, where the upper limit is given by:

$$
C=\frac{0.05 P_{\text {Rated }}}{V_{g}^{2} \omega}
$$

where:

$V_{g}$ : fundamental voltage of the grid

$\omega$ : fundamental frequency in radian per second

3) The series inductor $L_{f}$ is designed depending on the capacitance in the LLCL filters. For the zero impedance at the switching frequency,

$$
L_{f}=\frac{1}{\omega_{s w}^{2} C}
$$

4) The resonance frequency is in the range between ten times the fundamental frequency and a half of the switching frequency.

\section{PROPOSED ACTIVE DAMPING CONTROL}

Fig. 3 shows the control block diagram of the grid-connected T-type converter with the LLCL filters, where the PR control is applied for active damping.

\section{A. Active Damping Control}

The PR controller is operated in the $a b c$-reference frame, where the steady-state error is eliminated at the specified resonance frequency. The transfer function of the PR controller is given as

$$
G_{P R \_\mathrm{r}}(s)=K_{p r}+\frac{K_{r} s}{s^{2}+\omega_{r e s}^{2}}
$$

where:

$$
\begin{aligned}
& K_{p r} \text { : proportional gain } \\
& K_{r} \text { : resonant gain } \\
& \omega_{r e s} \text { : resonance frequency }
\end{aligned}
$$

The magnitude and phase characteristics of the open-loop transfer function for the PR controller with respect to the different resonant gains are illustrated in Fig. 4. It can be seen that the higher resonant gains can eliminate the steady-state error. However, this leads to a wider bandwidth. 

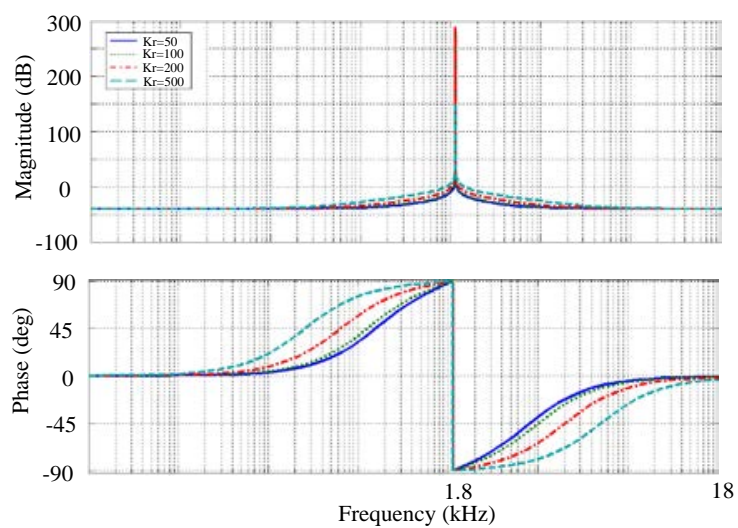

Fig. 4. Bode plots of the resonant controller for different gains $\left(K_{r}\right)$.

\section{B. Grid Impedance Estimation}

To suppress the resonance effectively, the grid impedance needs to be known. In this study, an online estimation of the grid impedance is applied to find the total inductance on the grid side of the LLCL filters [20]. When a voltage component of the specified frequency is added to the PWM voltage reference, a harmonic current component is incurred at the same frequency. Next, the Discrete Fourier analysis for the specific injected harmonic component is applied as:

$$
\begin{gathered}
\overline{F_{h}}=\sum_{n=0}^{N-1} g(n) \cos \left(\frac{2 \pi h n}{N}\right)-j \sum_{n=0}^{N-1} g(n) \sin \left(\frac{2 \pi h n}{N}\right) \\
\overline{F_{h}}=F_{h r}+j F_{h i}
\end{gathered}
$$

where:

$N$ : number of the samples per fundamental period

$g(n)$ :input signal (voltage or current) at the sampling point $n$

$$
\begin{aligned}
& \overline{F_{h}} \text { : complex Fourier vector of the } \mathrm{h}^{\text {th }} \text { harmonic of the } \\
& \quad \text { input signal } \\
& F_{h r}: \text { real part of } \overline{F_{h}} \\
& F_{h i}: \text { imaginary part of } \overline{F_{h}}
\end{aligned}
$$

Then, the harmonic current and voltage components are obtained from (12). From these the grid impedance at the specified harmonic frequency is calculated as:

$$
Z_{h_{x}}=\frac{V e^{j \varphi_{V}}}{I e^{j \varphi_{I}}}=Z e^{j \varphi_{Z}}=R_{\text {grid }}+j \omega_{h_{x}} L_{\text {grid }}
$$

where:

$R_{\text {grid }}$ : grid resistance at the injected harmonic $\mathrm{h}_{x}$.

$L_{\text {grid }}$ : grid inductance at the injected harmonic $h_{x}$.

The grid impedance in terms of the fundamental frequency is obtained by:

$$
\mathrm{Z}(60 \mathrm{~Hz})=R_{\text {grid }}+j \omega L_{\text {grid }}
$$

Fig. 5 illustrates variations of the filter resonance

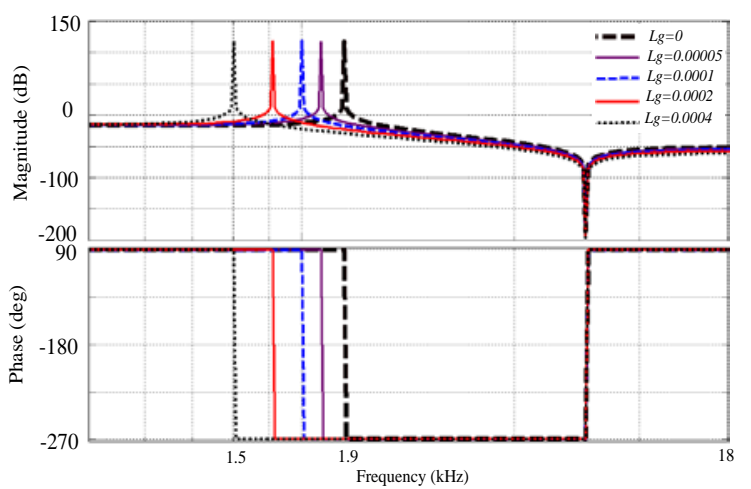

Fig. 5. Bode plots of transfer functions of LLCL filters for different values of grid inductance.

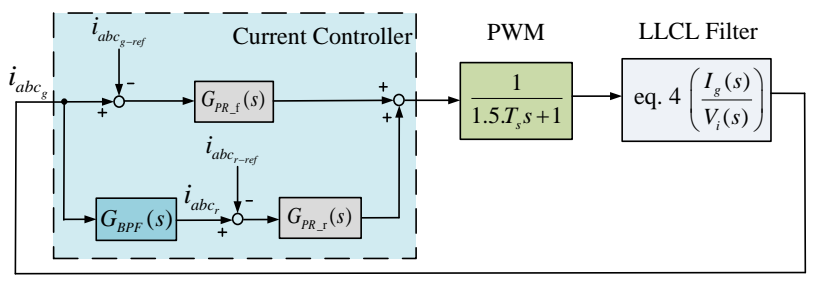

Fig. 6. The proposed closed-loop current control in stationary reference frame.

frequency according to variations of the grid impedance. By increasing the grid inductance from $L_{\text {grid }}=0$ to $0.5 \mathrm{mH}$ the filter resonance frequency, $f_{\text {res }}$, varies from $1.9 \mathrm{kHz}$ to 1.48 $\mathrm{kHz}$.

\section{STABILITY ANALYSIS}

To determine the feasibility of the proposed active damping method, the system stability is analyzed. The overall current control scheme is depicted in Fig. 6. Since the PI current controller $\left(G_{P I}(s)=K_{p}+K_{i} / s\right)$ is used in the synchronous reference frame, its equivalent form for the transfer function, $G_{P R_{-} \mathrm{f}}(s)$, in the stationary reference frame is given by:

$$
G_{P R_{-} \mathrm{f}}(s)=K_{p 1}+\frac{K_{r 1} s}{s^{2}+\omega_{o}^{2}}
$$

where:

$$
\begin{aligned}
& K_{p 1} \text { : proportional gain } \\
& K_{r 1} \text { : resonant control gain }
\end{aligned}
$$

A BPF (band-pass filter) is needed for the PR controller to damp the filter resonance, where the cut-off frequency is equal to the resonance frequency of the LLCL filters. The transfer function of the BPF is expressed as:

$$
G_{B P F}(s)=\frac{\frac{\omega_{b}}{Q} s}{s^{2}+\frac{\omega_{b}}{Q} s+\omega_{b}^{2}}
$$




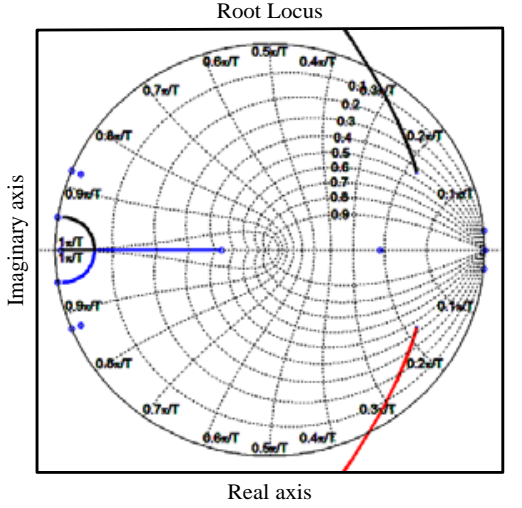

(a)

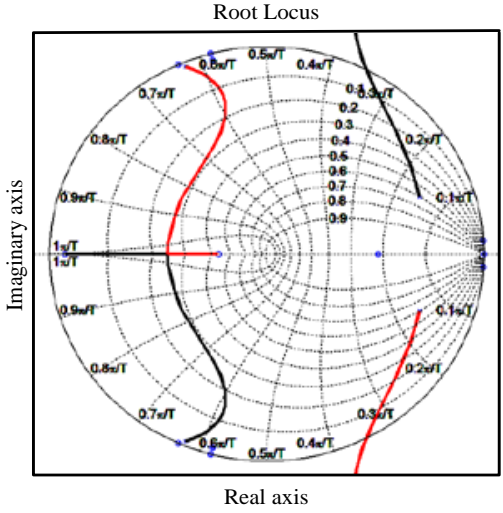

(b)

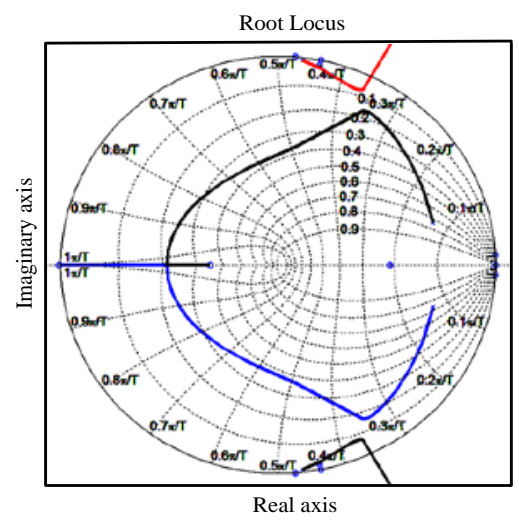

(c)

Fig. 7. Root loci of the proposed current control system. (a) $f_{s w}=4 \mathrm{kHz}$. (b) $f_{s w}=6 \mathrm{kHz}$. (c) $f_{s w}=8 \mathrm{kHz}$.

where:

$$
\begin{aligned}
& \omega_{b}: \text { center frequency } \\
& Q \text { : quality factor }\left(\frac{\omega_{b}}{B}\right)
\end{aligned}
$$$$
B \text { : bandwidth }
$$

Therefore, the transfer function of the current controller, $G_{c}(s)$, is the sum of $G_{P R_{-} f}(s)$ in (15) and the multiplication of $G_{P R_{-} r}(s)$ and $G_{B P F}(s)$ in (11) and (16) respectively, which can be expressed as:

$$
G_{c}(s)=G_{P R_{-}}(s)+G_{P R_{-} r}(s) G_{B P F}(s)
$$

The stability is evaluated in the Z-domain, where one sampling delay of the digital processing and one-half a sampling delay of the PWM converters are involved in the PWM block, which is expressed as:

$$
G_{P W M}(s)=\frac{1}{1.5 T_{s} s+1}
$$

Then, the open-loop transfer function of the current control system is expressed as:

$$
G_{o}=G_{P R_{-} f}(s) G_{P W M}(s) G_{1}(s)
$$

To analyze the frequency response of the proposed current control system, the closed-loop transfer function in (20) is investigated.

$$
G_{c}=\frac{G_{P R-\mathrm{f}}(s) G_{P W M}(s) G_{1}(s)}{-1+G_{c}(s) G_{P W M}(s) G_{1}(s)}
$$

The root loci for the proposed current control system are illustrated in Fig. 7. In Fig. 7(a), the root loci is plotted at the switching frequency of $f_{s w}=4 \mathrm{kHz}$. The control system is stable since all of the poles are placed inside the unit cycle. As the switching frequency is increased, the stability may be degraded. However, by tuning the controller gains, the system can still be stable at $f_{s w}=6 \mathrm{kHz}$ and $f_{s w}=8 \mathrm{kHz}$, as illustrated in Fig. 7(b) and (c), respectively.

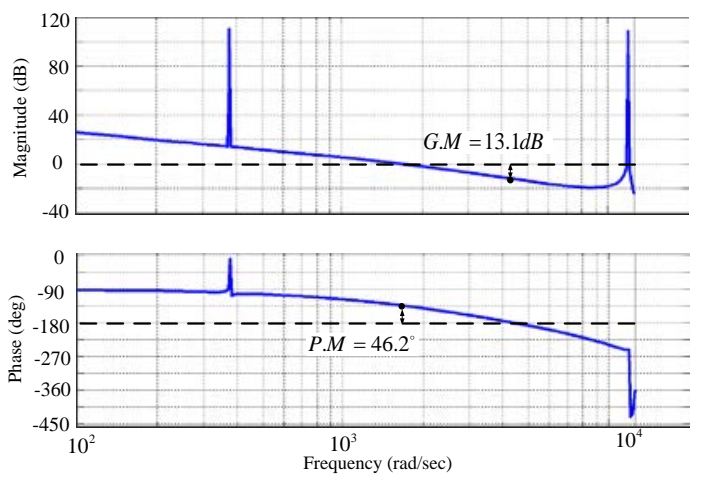

Fig. 8. Bode plot of the open-loop current control system.

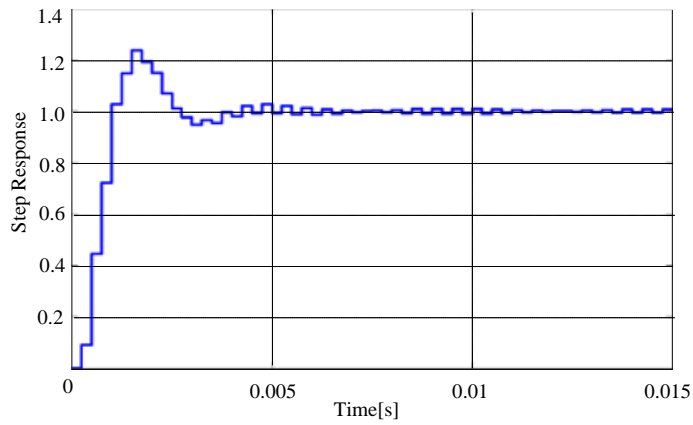

Fig. 9. Step response of the closed-loop current control system.

A further increase of the switching frequency may cause instability since the system poles are placed outside the unit cycle.

The frequency response of (19) is illustrated in Fig. 8 where the controller gains are $K_{p}=9, K_{i}=3000$, $K_{p r}=6, K_{i r}=50$ and the bandwidth of the controller is approximately $500 \mathrm{~Hz}$, which results from the definition of $G M=-3 d B$ in the closed-loop control system. A band-pass-filer (BPF) with a cut-off frequency of $1.9 \mathrm{kHz}$ and a bandwidth of $200 \mathrm{~Hz}$ are employed to extract the resonant components in the grid currents. In order to guarantee stability, a phase margin of $P M>45^{\circ}$ and a gain margin 
TABLE I

PWM CONVERTER PARAMETERS

\begin{tabular}{cc}
\hline Parameters & Value \\
\hline Rated Power & $25 \mathrm{~kW}$ \\
Input AC voltage & $380 \mathrm{~V}_{\mathrm{rms}} / 60 \mathrm{~Hz}$ \\
DC-link voltage & $600 \mathrm{~V}$ \\
Switching frequency & $4 \mathrm{kHz}$ \\
DC-link capacitance & $2,500 \mu \mathrm{F}$ \\
\hline
\end{tabular}

TABLE II

FILTER PARAMETERS

\begin{tabular}{|c|c|c|c|c|}
\hline Parameters & \multicolumn{2}{|c|}{ LLCL } & \multicolumn{2}{c|}{ LCL } \\
\hline \hline $\begin{array}{c}\text { Converter-side inductor } \\
\mathrm{L}_{1}(\mathrm{mH}), \text { Grid-side } \\
\text { Inductor } \mathrm{L}_{2}(\mathrm{mH})\end{array}$ & $\mathrm{L}_{1}$ & $\mathrm{~L}_{2}$ & $\mathrm{~L}_{1}$ & $\mathrm{~L}_{2}$ \\
\cline { 2 - 5 } & 1.2 & 0.35 & 1.2 & 0.35 \\
\hline Capacitor $(\mu \mathrm{F})$ & \multicolumn{2}{|c|}{20} & \multicolumn{2}{|c|}{20} \\
\hline Series inductor $(\mu \mathrm{H})$ & \multicolumn{2}{|c|}{80} & \multicolumn{2}{|c|}{0} \\
\hline
\end{tabular}

$G M>6 d B$ are generally desirable [13], [21]. Fig. 8 shows that the gain and phase margins of the open-loop current control system are $13 \mathrm{~dB}$ and $46^{\circ}$, respectively.

Fig. 9 shows the step responses of the closed-loop system in (20), where a resonance phenomenon does not appear.

\section{Simulation Results}

A simulation is performed for the three-level T-type PWM converter. The simulation parameters are listed in Table I. The different parameters of the filters are shown in Table II.

Fig. 10 illustrates the performance of the grid impedance estimation. The estimated and real values of the grid inductance are shown in (a), where the estimation error is less than 5\%. In (b), the magnitude of the injected harmonic and its frequency are shown. The distortion in the grid current, due to the harmonic injection, appears as shown in (c). In (d), the resonance frequency of the LLCL filters for different grid impedances is illustrated, where the resonance frequency varies from $1.9 \mathrm{kHz}$ in the case of zero grid impedance to $1.48 \mathrm{kHz}$ in the case of a grid impedance of $0.5 \mathrm{mH}$.

Fig. 11 shows the grid and converter currents and the FFT spectra in the case $\mathrm{I}\left(\mathrm{L}_{1}=1.2 \mathrm{mH}, \mathrm{L}_{2}=0.8 \mathrm{mH}\right)$ of LCL filters. The magnitude of the dominant harmonic component in the grid current is lower than $0.1 \mathrm{~A}(0.18 \%$ of the fundamental component). The total harmonic distortion (THD) factors are listed in Table III. For this Case I the THD is 2.91\%.

Case II of the LCL filters $\left(\mathrm{L}_{1}=1.2 \mathrm{mH}, \mathrm{L}_{2}=0.35 \mathrm{mH}\right)$ is illustrated in Fig. 12, where the dominant harmonic magnitude in the grid current is lower than $0.3 \mathrm{~A}(0.56 \%$ of the fundamental current) with a THD of $5.12 \%$. It is obvious that Case II of the LCL filters does not meet the requirement

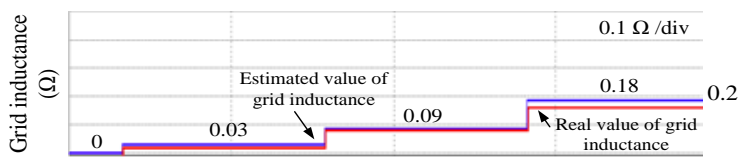

(a)

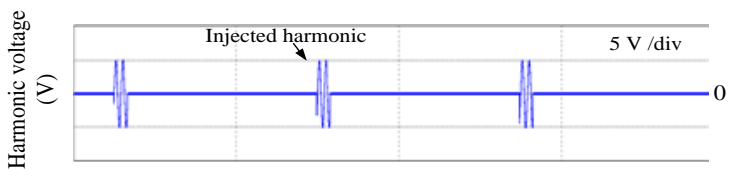

(b)

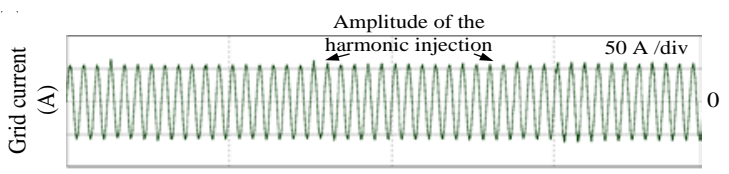

(c)

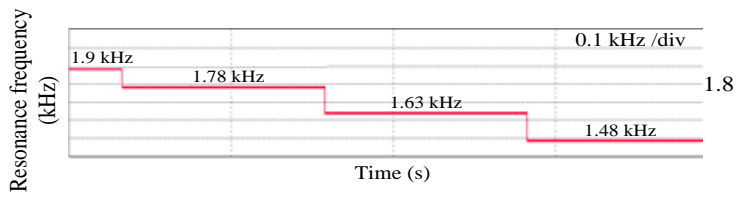

(d)

Fig. 10. Grid impedance estimation. (a) Grid inductance. (b) Harmonic voltage. (c) Grid current. (d) Resonance frequency.
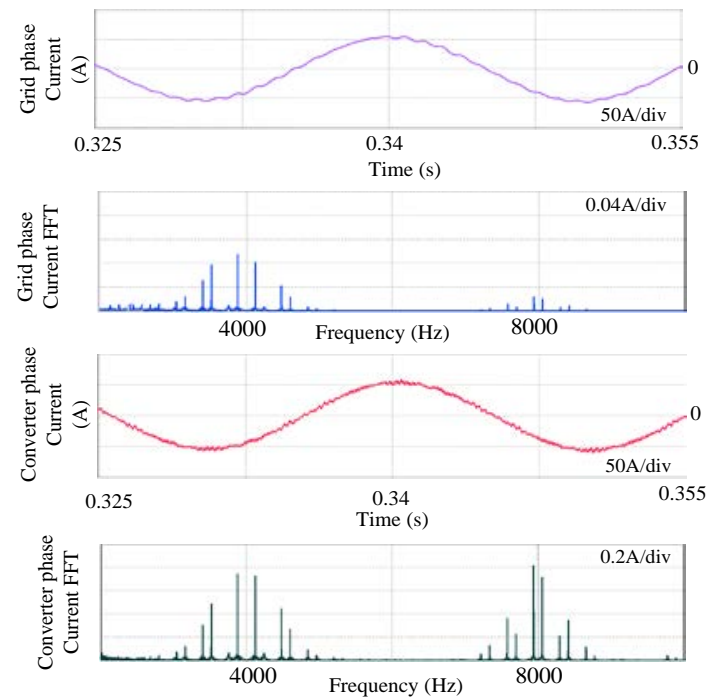

Fig. 11. Grid and converter currents with FFT spectra in case I of LCL filters: $\mathrm{L}_{1}=1.2 \mathrm{mH}, \mathrm{L}_{2}=0.8 \mathrm{mH}$.

of the IEEE standard 519-1992.

Case III of the LLCL filters $\left(\mathrm{L}_{1}=1.2 \mathrm{mH}, \mathrm{L}_{2}=0.35 \mathrm{mH}\right.$, and $\mathrm{L}_{\mathrm{f}}=0.08 \mathrm{mH}$ ) is shown in Fig. 13, where the magnitude of the dominant harmonic in the grid current is lower than $0.92 \mathrm{~A}(0.17 \%$ of the fundamental component) with a THD of $2.64 \%$ (Table III).

\section{EXPERIMENTAL RESULTS}

To verify the proposed damping control, experiments have been conducted on a 3-kW converter system. A 32-b DSP 
TABLE III

THD And Sideband HaRmonic Magnitude of The GRID CURRENT IN DIFFERENT CASES

\begin{tabular}{|c|c|c|c|}
\hline & $\begin{array}{c}\text { Case I: } \\
\text { LCL }\end{array}$ & $\begin{array}{c}\text { Case II: } \\
\text { LCL }\end{array}$ & $\begin{array}{c}\text { Case III: } \\
\text { LLCL }\end{array}$ \\
\hline THD (\%) & 2.91 & 5.12 & 2.64 \\
\hline $\begin{array}{c}\text { Dominant harmonic } \\
\text { magnitude per } \\
\text { fundamental (\%) }\end{array}$ & 0.18 & 0.56 & 0.17 \\
\hline
\end{tabular}
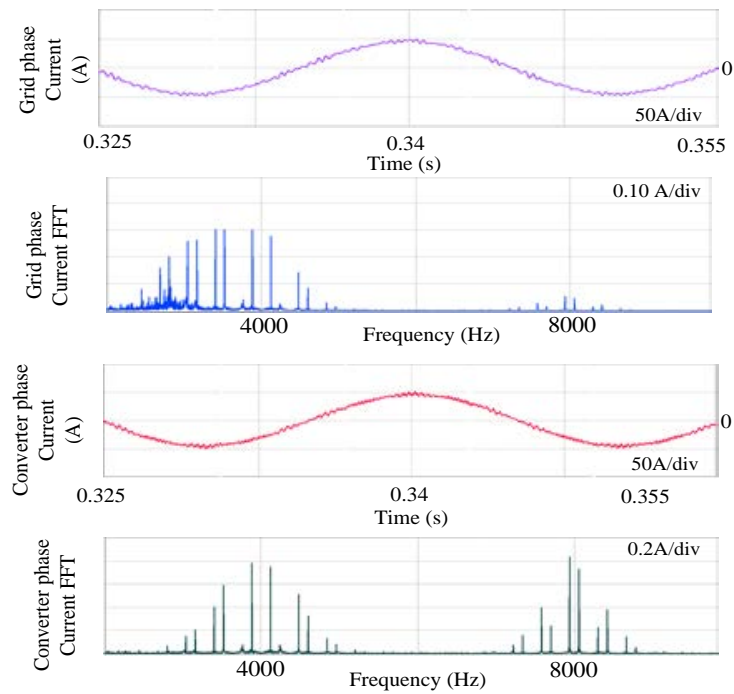

Fig. 12. Grid and converter currents with FFT spectra in case II of LCL filters: $\mathrm{L}_{1}=1.2 \mathrm{mH}, \mathrm{L}_{2}=0.35 \mathrm{mH}$.
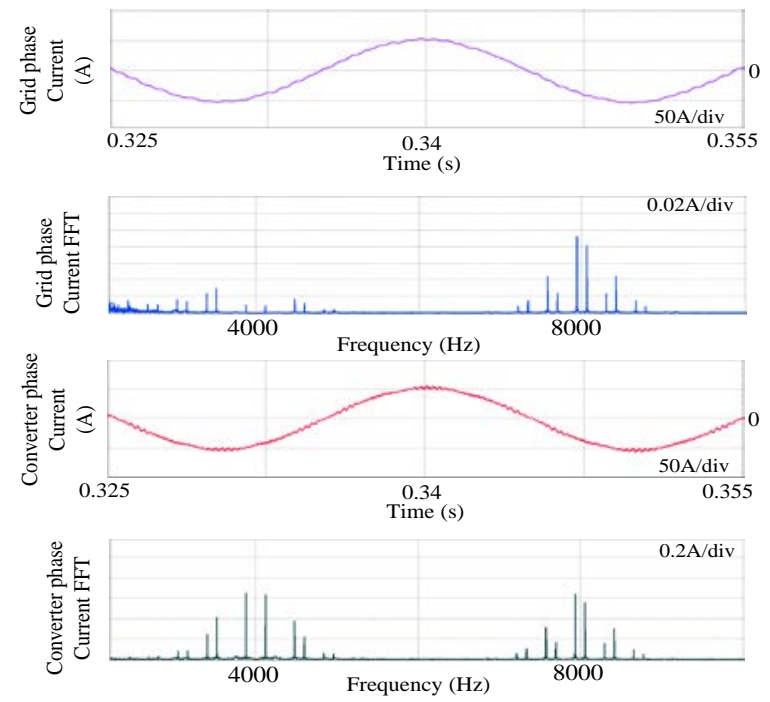

Fig. 13. Grid and converter currents with FFT spectra in case III of LLCL filters: $\mathrm{L}_{1}=1.2 \mathrm{mH}, \mathrm{L}_{2}=0.35 \mathrm{mH}, \mathrm{L}_{\mathrm{f}}=0.08 \mathrm{mH}$.

chip (TMS320F28335) is used for the main controller. The parameters of the three-level T-type converter are listed in Table. IV. The PWM frequency of the converter is $5 \mathrm{kHz}$ and the dead time is set to $2 \mu \mathrm{s}$. For the IGBT module (4MBI300VG-120R-50), two gating drivers have been employed such as VLA513-01R for the mid-point IGBTs and

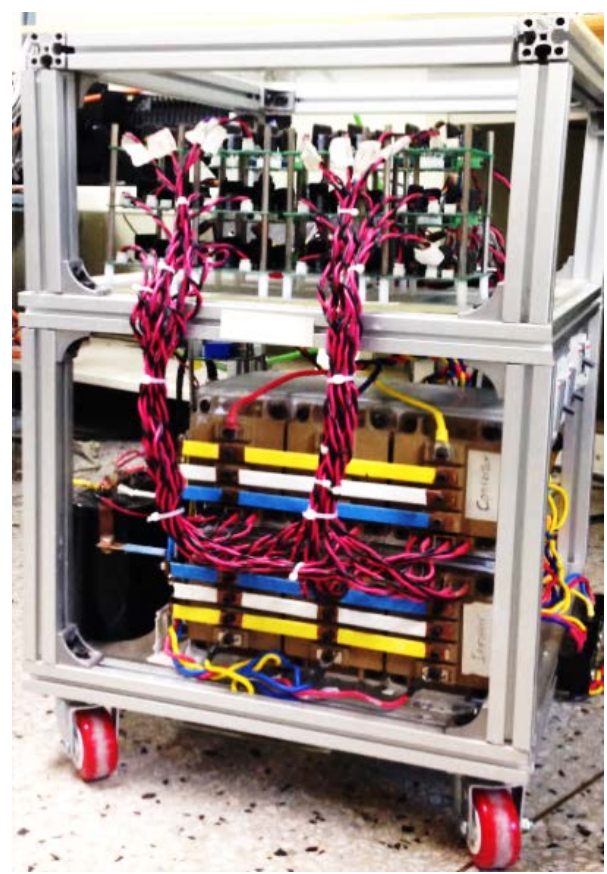

Fig. 14. Three-level T-type PWM converter.

TABLE IV

PWM CONVERTER PARAMETERS

\begin{tabular}{cc}
\hline Parameters & Value \\
\hline Power rating & $3 \mathrm{~kW}$ \\
Input AC voltage & $220 \mathrm{~V}_{\mathrm{rms}} / 60 \mathrm{~Hz}$ \\
DC-link voltage & $340 \mathrm{~V}$ \\
Switching frequency & $5 \mathrm{kHz}$ \\
DC-link capacitance & $2,500 \mu \mathrm{F}$ \\
\hline
\end{tabular}

TABLE V

FILTER PARAMETERS

\begin{tabular}{|c|c|c|c|c|}
\hline Parameters & \multicolumn{2}{|c|}{ LLCL } & \multicolumn{2}{c|}{ LCL } \\
\hline $\begin{array}{c}\text { Converter-side inductor } \\
\mathrm{L}_{1}(\mathrm{mH}), \text { Grid-side } \\
\text { Inductor } \mathrm{L}_{2}(\mathrm{mH})\end{array}$ & $\mathrm{L}_{1}$ & $\mathrm{~L}_{2}$ & $\mathrm{~L}_{1}$ & $\mathrm{~L}_{2}$ \\
\cline { 2 - 5 } & 2 & 0.4 & 2 & 0.4 \\
\hline Capacitor $(\mu \mathrm{F})$ & \multicolumn{2}{|c|}{10} & \multicolumn{2}{|c|}{10} \\
\hline Series inductor $(\mu \mathrm{H})$ & \multicolumn{2}{|c|}{100} & \multicolumn{2}{|c|}{0} \\
\hline
\end{tabular}

VLA542-01 for the leg IGBTs. For the reduced-scale system of the simulation, the LLCL filters are redesigned by the same procedure described in section II (Table. V). Fig. 14 shows the three-level T-type PWM converter used for the tests.

The grid and converter currents and the FFT spectra are shown in Fig. 15, for Case I of the LCL filters $\left(\mathrm{L}_{1}=2 \mathrm{mH}\right.$, $\mathrm{L}_{2}=1 \mathrm{mH}$ ) where the magnitude of the dominant harmonic component in the grid current is lower than $0.021 \mathrm{~A}(0.2 \%$ of the fundamental component) with a THD of 3.72\%.

Fig. 16 illustrates the same waveforms as in Fig. 15, in Case II of the LCL filters $\left(\mathrm{L}_{1}=2 \mathrm{mH}, \mathrm{L}_{2}=0.4 \mathrm{mH}\right)$, where the 

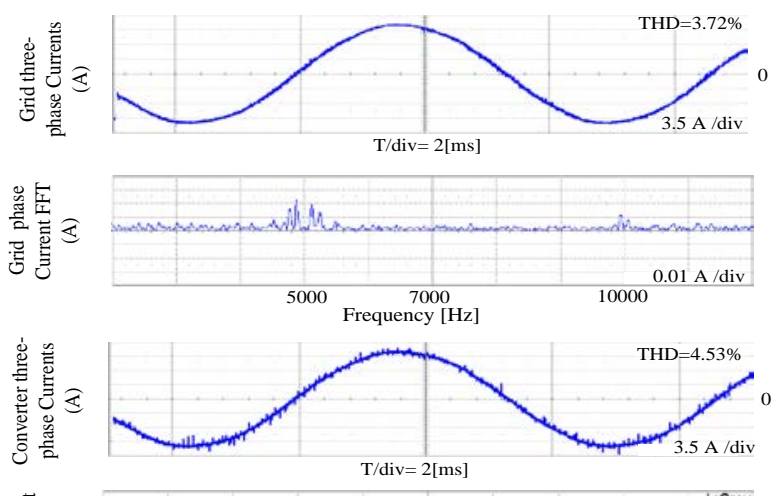

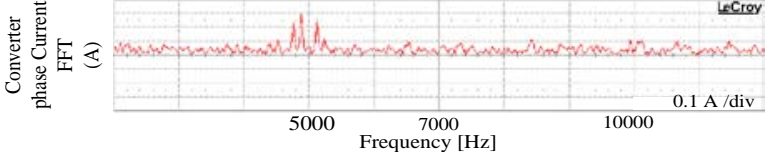

Fig. 15. Grid and converter currents with FFT spectra in the case I of LCL filters $\left(\mathrm{L}_{1}=2 \mathrm{mH}, \mathrm{L}_{2}=1 \mathrm{mH}\right)$.
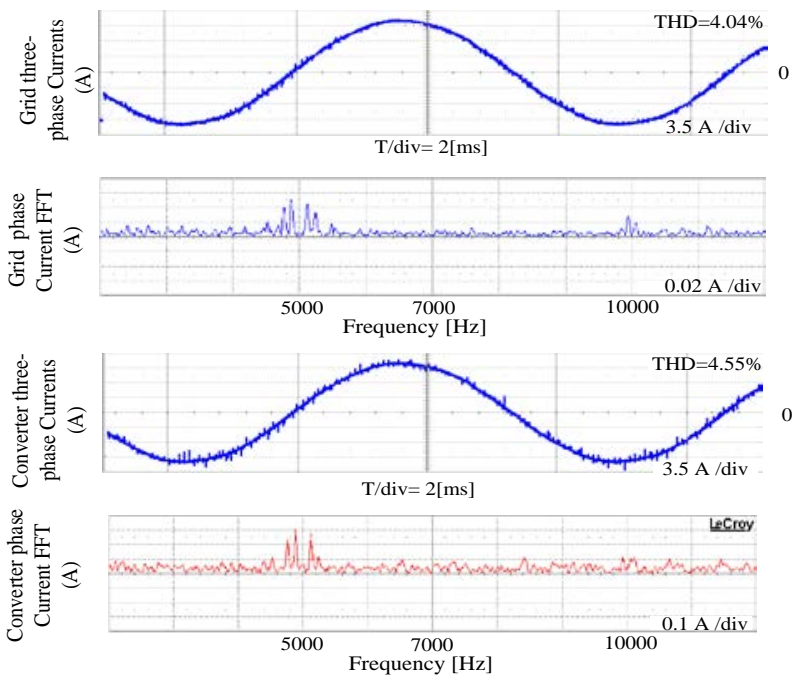

Fig. 16. Grid and converter currents with FFT spectra in the case II of LCL filters: $\mathrm{L}_{1}=2 \mathrm{mH}, \mathrm{L}_{2}=0.4 \mathrm{mH}$.

TABLE VI

THD AND SidEBAND HARMONICS MAgNitUde OF THE GRID CURRENT IN DifFERENT CASES

\begin{tabular}{|c|c|c|c|}
\hline & $\begin{array}{c}\text { Case I: } \\
\text { LCL }\end{array}$ & $\begin{array}{c}\text { Case II: } \\
\text { LCL }\end{array}$ & $\begin{array}{c}\text { Case III: } \\
\text { LLCL }\end{array}$ \\
\hline THD (\%) & 3.72 & 4.04 & 2.47 \\
\hline $\begin{array}{c}\text { Dominant harmonic } \\
\text { magnitude per } \\
\text { fundamental (\%) }\end{array}$ & 0.2 & 0.46 & 0.13 \\
\hline
\end{tabular}

dominant harmonic magnitude in the grid current is lower than $0.052 \mathrm{~A}(0.46 \%$ of the fundamental current) with a THD of $4.04 \%$. It is obvious that Case II of the LCL filters does not meet the requirement of the IEEE standard. In Case III of the LLCL filters $\left(\mathrm{L}_{1}=2 \mathrm{mH}, \mathrm{L}_{2}=0.4 \mathrm{mH}\right.$, and $\mathrm{L}_{\mathrm{f}}=0.1$ $\mathrm{mH}$ ), as shown in Fig. 17, the magnitude of the dominant harmonic in the grid current is lower than $0.015 \mathrm{~A}(0.13 \%$ of the fundamental component) with a THD of $2.47 \%$ (Table
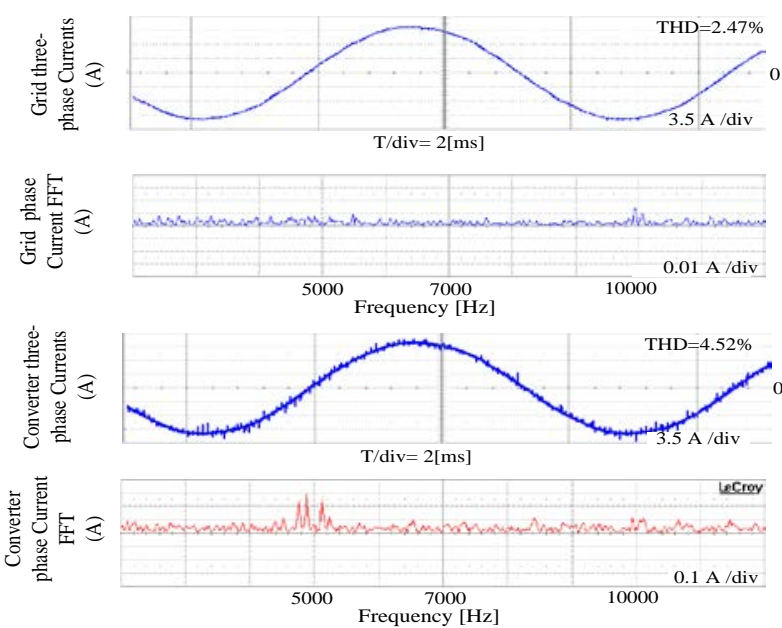

Fig. 17. Grid and converter currents with FFT spectra in case III of LLCL filters: $\mathrm{L}_{1}=2 \mathrm{mH}, \mathrm{L}_{2}=0.4 \mathrm{mH}, \mathrm{L}_{\mathrm{f}}=0.1 \mathrm{mH}$.

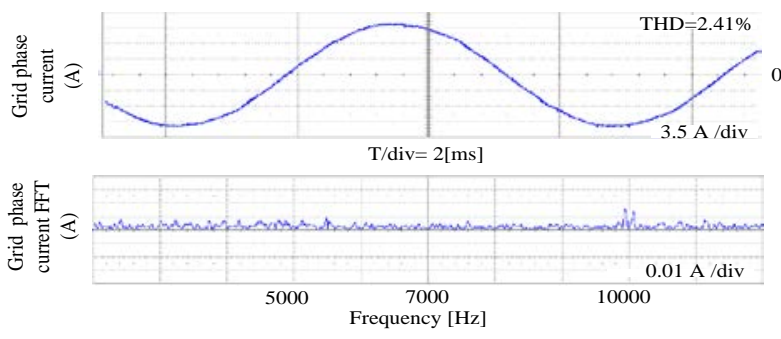

(a)

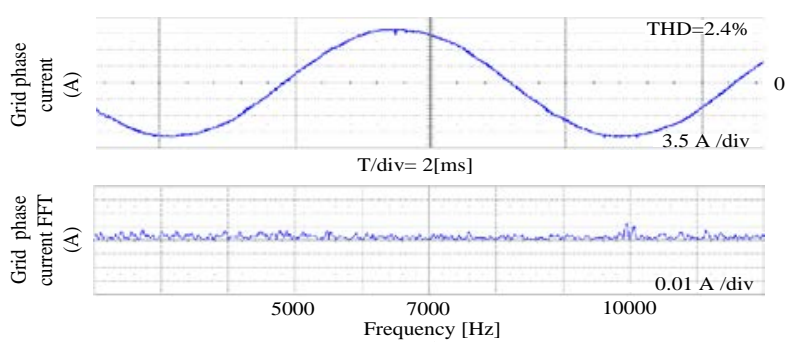

(b)

Fig. 18. Grid currents and FFT spectra with LLCL filters. (a) $\mathrm{L}_{\text {grid }}=0.1 \mathrm{mH}$. (b) $\mathrm{L}_{\text {grid }}=0.2 \mathrm{mH}$.

VI).

Fig. 18 shows the grid phase currents and FFT spectra in the case of different grid impedances. Even though the grid impedance is changed from $0.1 \mathrm{mH}$ to $0.2 \mathrm{mH}$, the PR controller can suppress the resonance effectively with the estimated grid impedance. In addition, a THD of about $2.4 \%$ in the grid currents is within the acceptable level.

Fig. 19 shows the converter performance in the case of a resistive load application, where the grid current and the q-axis converter current are shown in (a) and (b), respectively. The DC-link voltage is fluctuated at the point where the converter q-axis current changes abruptly, where the undershoot in the DC-link voltage is lower than $10 \%$ as shown in (c). The converter phase current is illustrated in (d). As can be seen, it is more distorted than the grid current. 


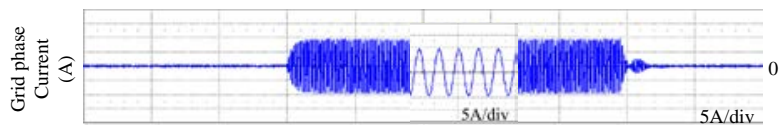

(a)

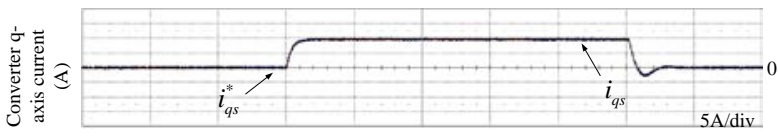

(b)

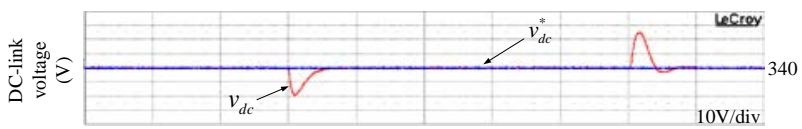

(c)

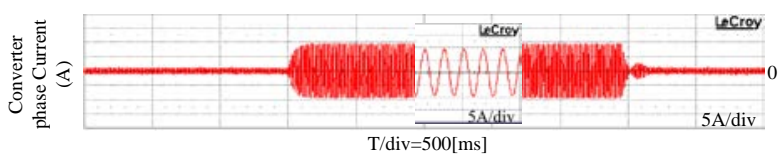

(d)

Fig. 19. Converter control performance with LLCL filters. ( $\mathrm{L}_{1}$ $=2 \mathrm{mH}, \mathrm{L}_{2}=0.4 \mathrm{mH}$, and $\mathrm{L}_{\mathrm{f}}=0.10 \mathrm{mH}$ ). (a) Grid phase current. (b) Converter q-axis current. (c) DC-link voltage. (d) Converter phase current.

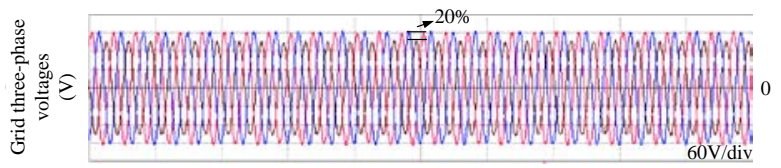

(a)

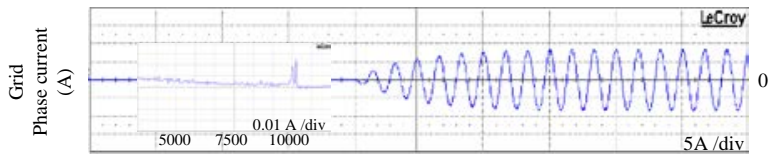

(b)

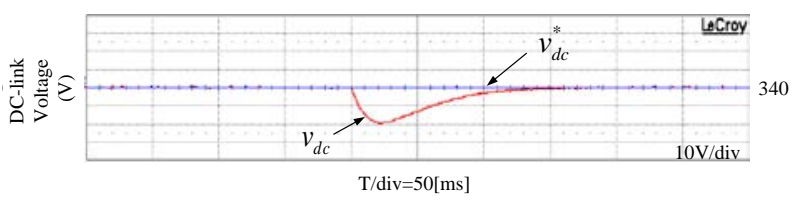

(c)

Fig. 20. Converter control performance with LLCL filters in the case of $20 \%$ drop in grid voltage. $\left(\mathrm{L}_{1}=2 \mathrm{mH}, \mathrm{L}_{2}=0.4 \mathrm{mH}\right.$, and $\mathrm{L}_{\mathrm{f}}=0.1 \mathrm{mH}$ ). (a) Grid three-phase voltages. (b) Grid phase current (c) DC-link voltage.

Fig. 20 shows the performance of the converter in the case of unbalanced grid voltages, where one phase-voltage of the grid is decreased by $20 \%$ as shown in (a). The grid phase current in the case of resistive load variations is shown in (b), where the switching ripples meet the IEEE standard of $0.3 \%$. The fluctuations in the DC-link voltage do not exceed $10 \%$ as shown in (c), which is acceptable under this condition.

\section{CONCLUSION}

In this paper, an active damping method using a PR controller has been proposed for the LLCL filters connected to the three-level T-type PWM converter. In addition, the grid impedance has been estimated online to compensate for the resonance frequency of the filter in the case of a variable grid impedance. The damping effect of the PR controller on LLCL filters has been verified by simulation and experimental results. In the LLCL filters, the grid-side inductor has been reduced by $60 \%$, when compared with the LCL filters, from $0.8 \mathrm{mH}$ to $0.35 \mathrm{mH}$ in the simulation and from $1 \mathrm{mH}$ to 0.4 $\mathrm{mH}$ in the experiment. In this case, the THD and dominant harmonic component of the grid current have met the IEEE standard. It has been shown that the control performance for the LLCL filters is satisfactory both in the transient state and under grid voltage unbalances.

\section{ACKNOWLEDGMENT}

This research was supported by Basic Science Research Program through the National Research Foundation of Korea (NRF) funded by the Ministry of Education (2012R1A1A4A01015362).

\section{REFERENCES}

[1] J. Rodriguez, J.-S. Lai, and F. Z. Peng, "Multilevel inverters: A survey of topologies, controls, and applications,” IEEE Trans. Ind. Applicat., Vol. 49, No. 3, pp. 724-738, Aug. 2002.

[2] M. Schweizer, and J. W. Kolar, "Design and implementation of a highly efficient three-level T-type converter for low-voltage applications," IEEE Trans. Power Electron., Vol. 28, No. 2, pp. 899-907, Feb. 2013.

[3] M. Liserre, F. Blaabjerg, and S. Hansen, "Design and control of an LCL-filter-based three-phase active rectifier,” IEEE Trans. Ind. Applicat., Vol. 41, No. 5, pp. 1281-1291, Sep./Oct. 2005.

[4] E. Twining and D. G. Holmes, "Grid current regulation of a three- phase voltage source inverter with an LCL input filter," IEEE Trans. Power Electron., Vol. 18, No. 3, pp. 888-895, Feb. 2003.

[5] J. Dannehl, C. Wessels, and F. Fuchs, "Limitations of voltage-oriented PI current control of grid-connected PWM rectifiers with LCL filters," IEEE Trans. Ind. Electron., Vol. 56, No. 2, pp. 380-388, Feb. 2009.

[6] I. J. Gabe, V. F. Montagner, and H. Pinheiro, "Design and implementation of a robust current controller for VSI connected to the grid through an LCL filter," IEEE Trans. Power Electron., Vol. 24, No. 6, pp. 1444-1452, Jun. 2009.

[7] Z. Zeng, J.-Q. Yang, S.-L. Chen, and J. Huang, “Co-design of the LCL filter and control for grid-connected inverters," Journal of Power Electronics, Vol. 14, No. 4, pp. 1-10, Jul. 2014.

[8] R. P-Alzola, M. Liserre, F. Blaabjerg, R. Sebastian, J. Dannehl, and F. Wilhelm Fuchs, "Analysis of the passive damping losses in $L C L$-filter-based grid converters," IEEE Trans. Power Electron., Vol. 28, No. 6, pp. 2642-2646, Jun. 2013.

[9] W. Wu, Y. He, T. Tang, and F. Blaabjerg, “A new design method for the passive damped LCL and LLCL filter based single phase grid tied inverter," IEEE Trans. Ind. Appl., Vol. 60, No. 10, pp. 4339-4349, Oct. 2013. 
[10] W. Wu, Y. Sun, M. Huang, X. Wang, F. Blaabjerg, M. Liserre, and H. S.-h. Chung, "A robust passive damping method for LLCL-filter-based grid-tied inverters to minimize the effect of grid harmonic voltages," IEEE Trans. Power Electron., Vol. 29, No. 7, pp. 3279-3289, Jul. 2014.

[11] Byoung-Woong An, Chang-Pyo Hong, Hag-Won Kim, Kwan-Yuhl Cho, and Byung-Kuk Lim, "A Study on LLCL Filter to Reduce Harmonic Current of Grid Connected Power Inverter," Transactions of Korean Institute of Power Electronics(KIPE), Vol. 19, No. 1, pp. 64-70, Feb. 2014.

[12] P. A. Dahono, "A control method for dc-dc converter that has an LCL output filter based on new virtual capacitor and resistor concepts,” in Proc. IEEE PESC, pp. 36-42, 2004.

[13] C. Wessels, J. Dannehl, and F. W. Fuchs, “Active damping of LCL filter resonance based on virtual resistor for PWM rectifiers-stability analysis with different filter parameters," in Proc. IEEE PESC, pp. 3532-3538, 2008.

[14] M. Liserre, A. Dell'Aquila, and F. Blaabjerg, “Genetic algorithm-based design of the active damping for an LCL-filter three-phase active rectifier," IEEE Trans. Power Electron., Vol. 19, No. 1, pp. 76-86, Jan. 2004.

[15] R. Teodorescu, F. Blaabjerg, U. Borup, and M. Liserre, “A new control structure for grid-connected lcl pv inverters with zero steady-state error and selective harmonic compensation," in Proc. IEEE APEC'04, Vol. 1, pp. 580-586, 2004.

[16] P. Alemi and D.-C. Lee, "Active damping control of LLCL filters for three-level T-type grid converters," in Proc. IPEC 2014-ECCE Asia, pp. 1201-1206, 2014.

[17] Z. Zeng, J.-Q. Yang, S.-L. Chen, and J. Huang, "Fast transient repetitive control strategy for a three-phase LCL filter based shunt active power filter," Journal of Power Electronics, Vol. 14, No. 2, pp. 392-401, Mar. 2014.

[18] W. Wu and F. Blaabjerg, "An LLCL power filter for single-phase grid-tied inverter," IEEE Trans. Power Electron., Vol. 27, No. 2, pp. 782-789, Feb. 2012.

[19] S.-K. Sul, Control of Electric Machine Drive Systems, IEEE Press, 2011.

[20] L. Asiminoaei, R. Teodorescu, F. Blaabjerg, and U. Borup, "A digital controlled PV-inverter with grid impedance estimation for ENS detection," IEEE Trans. Power Electron., Vol. 20, No. 6, pp. 1480-1490, Nov. 2005.

[21] X.-Q. Li, X.-J. Wu, Y.-W. Geng, and Q. Zhang, "Stability analysis of grid-connected inverters with an LCL filter considering grid impedance," Journal of Power Electronics, Vol. 13, No. 5, pp. 896-908, Sep. 2013.

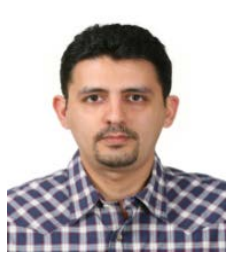

Payam Alemi was born in Tabriz, Iran, in 1982. He received his B.S. degree from the University of Tabriz, Tabriz, Iran, in 2005, and his M.S. degree from the Science and Research Branch, Islamic Azad University, Tehran, Iran, in 2008, and Ph.D. degree in Electrical Engineering, from Yeungnam University, Gyeongsan, Korea, in 2014. His current research interests include the control of multilevel power converters, power loss analysis for converters, LCL filters and machine drives.

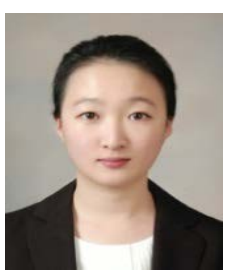

Seon-Yeong Jeong was born in 1988. She received her B.S. and M.S. degrees in Electrical Engineering from Yeungnam University, Gyeongsan, Korea, in 2011 and 2014, respectively. Her current research interests include converter control and power quality.

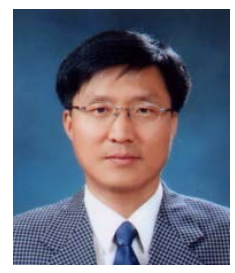

Dong-Choon Lee received his B.S., M.S., and Ph.D. degrees in Electrical Engineering from Seoul National University, Seoul, Korea, in 1985, 1987, and 1993, respectively. He was a Research Engineer with Daewoo Heavy Industry, Korea, from 1987 to 1988 . Since 1994, he has been a faculty member in the Department of Electrical Engineering, Yeungnam University, Gyeongsan, Korea. As a Visiting Scholar, he joined the Power Quality Laboratory, Texas A\&M University, College Station, TX, USA, in 1998; the Electrical Drive Center, University of Nottingham, Nottingham, UK, in 2001; the Wisconsin Electric Machines and Power Electronic Consortium, University of Wisconsin, Madison, WI, USA, in 2004; and the FREEDM Systems Center, North Carolina State University, Raleigh, NC, USA, from September 2011 to August 2012. His current research interests include ac machine drives, the control of power converters, wind power generation, and power quality. Professor Lee is currently the Editor-in-Chief for the Journal of Power Electronics of the Korean Institute of Power Electronics. 